\title{
EFFECT OF LONG-TERM SUCCESSIVE STORM FLOWS ON WATER RECLAMATION PLANT RESILIENCE
}

Jun-Jie Zhu ${ }^{\mathrm{a}}$ and Paul R. Anderson*

Department of Civil, Architectural and Environmental Engineering, Illinois Institute of Technology, Chicago, IL 60616-3793, United States.

${ }^{\mathrm{a} E m a i l: ~ j z h u 21 @ i i t . e d u ~}$

*Corresponding Author

Telephone: 312-567-3531. Email: andersonp@iit.edu. 


\begin{abstract}
A water reclamation plant (WRP) needs to be resilient to successfully operate through different kinds of perturbations. Perturbations such as storm events, especially long-term successive storm flows, can adversely affect operations. A better understanding of these effects can provide benefits for plant operation, in terms of effluent quality and energy efficiency. However, the concept of resilience for a WRP has not been widely studied, and we are not aware of any studies specifically related to storm flows. In this work we applied measures of resistance and recovery time to quantify resilience, and used a WRP simulation model to investigate how different storm flow characteristics (flowrate and duration) and the amount of aeration influence resilience. Not surprisingly, increasing storm flowrate leads to decreasing resilience. Although the aeration rate plays an important role in determining resilience, there is an aeration threshold $\left(6 \mathrm{~m}^{3} / \mathrm{s}\right.$ for our WRP model); higher aeration rates do not increase resilience. Results suggest that aeration costs could be reduced by as much as $50 \%$ while still maintaining the resilience needed to meet effluent quality permit requirements through the perturbations examined in this study.
\end{abstract}

Key words: Storm flows, water reclamation plant, resilience, recovery time, resistance, energy 


\section{Introduction}

This paper describes how monitoring and control information can promote more efficient operation at the Metropolitan Water Reclamation District of Greater Chicago (MWRDGC) Calumet water reclamation plant (WRP). The work is part of a collaborative project involving the MWRDGC and the Illinois Institute of Technology (IIT), to reduce energy demands and to improve control of nutrient loading in the Chicago Area Waterway System (CAWS) (CPS 2010). To provide more efficient operations at the Calumet WRP, it is important to understand how influent conditions, effluent quality, and the energy requirements for aeration are related. To assess these relationships, we simulated process response to long-term successive storm flows using a WRP process model, and used resistance and recovery time to quantify process resilience. A brief introduction of the motivation of this study is provided below, followed by a review of related, relevant studies, which helped us to define and develop a method to quantify WRP process resilience.

The concept of resilience was initially developed in the ecological sciences to describe the capacity of an ecosystem to tolerate disturbances that significantly influence the function and structure of that ecosystem (Holling 1973; Westman 1978; Lopez et al. 2013). Grimm and Wissel (1997) suggested that resilience has been confused with "stability" in ecological studies; the confusion stems from the fact that resilience is a quantitative index, whereas stability is a qualitative property. Holling (1996) suggested that the concept of resilience could also be applied to engineered processes, but there was a difference between ecological resilience and engineering resilience: 
- Ecological resilience is the amount of disturbance a system can withstand before its function changes.

- Engineering resilience has two components; one is the resistance to the disturbance and one is the time to return to an acceptable steady-state.

Holling (1996) concluded that ecological resilience involved maintaining system function, but engineering resilience focused on the efficiency of that function (such as, to achieve a single operating objective). Whereas ecological resilience can apply to several different states, engineering resilience focuses on the designed state (Peterson et al. 1998; Botton et al. 2006). Because a WRP is an engineered microbial ecosystem, it is helpful to review how these perspectives have been applied in previous studies, and how those studies interpreted and measured resilience.

In previous studies that applied the concept of engineering resilience it was common to treat the resistance as an independent parameter, and define resilience as a function of the return time. For example, Wertz et al. (2007) investigated the effect of decreasing soil microbial diversity on resistance and resilience in response to a disturbance (heat). They measured resistance and resilience based on function and diversity of denitrifiers and nitrite oxidizers. Cabrol et al. (2012) assessed resistance and resilience for a gas biofilter, based on changes in the removal efficiency (RE) with respect to several constituents, when the biofilter was exposed to shock loading. They defined the resistance as the percentage of time-integrated RE during the shock loading relative to a reference RE without shock loading. They also calculated resilience based on the time required after the shock loading to return to $95 \%$ of the original stable RE. A few researchers have focused specifically on microbial ecosystems in wastewater treatment. For example, 
Saikaly and Oerther (2011) measured the resistance of an activated sludge microbial community to a toxic shock loading. They quantified the resistance as the concentration of toxicant that can result in 50\% reduction (relative to a reference control experiment without toxicant) of oxygen uptake rate during a 30 min exposure to that toxic loading. More recently, Marsolek et al. (2014) used resistance and resilience to measure bioreactor performance with respect to microbial diversity and perturbations (based on exposure to 2,4,5-trichlorophenol) in wastewater treatment. They quantified the response based on the ratio of system performance following a perturbation (on day 1), to performance under steady-state conditions. Resistance was defined as the value of that ratio on days 2, 4, and 6 , and resilience was defined as that ratio on days 10 and 11 .

Because a WRP is an engineered ecosystem that uses controls to manage a microbial ecosystem, we were most interested in describing resilience in the context of engineered controls. The existing literature contains little information about WRP resilience, especially related to wet-weather perturbations. For example, Mabrouk et al. (2010) defined the return time as the time required until the excess pollution concentration returned to the permit limit value following a perturbation, and examined how return time could be used to quantify resilience. Weld and Singh (2011) compared the resilience of each component in a hybrid anaerobic digester/microbial fuel cell system based on a perturbation in the acetic acid concentration. They used the time for the $\mathrm{pH}$ to recover to its original value as an indicator for resilience. Weirich et al. (2015) used part of the U.S. Environmental Protection Agency's Integrated Compliance Information System WRP data to develop time series generalized linear models for BOD, TSS, ammonia, and fecal coliform concentrations. They used the models to simulate ten years of results to evaluate 
resilience and stability, which were defined as the recovery time after a violation and the frequency of violation, respectively.

Methods from the studies summarized above suggest that recovery time or/and resistance can be used to better understand process resilience at a WRP, and that parameters such as $\mathrm{RE}$, pollutant concentration, $\mathrm{pH}$, or effluent quality can be used to monitor system response to perturbations. In our study we used resistance and recovery time as indicators of resilience; these indicators were evaluated based on a critical constituent, which we defined as the constituent with the longest recovery time.

Our study focused on the MWRDGC Calumet WRP, which began operations in 1922 and now serves more than one million people. The plant treats about $11.4 \mathrm{~m}^{3} / \mathrm{s}(260 \mathrm{mgd})$ of wastewater and uses an activated sludge process (including nitrification) in all five batteries (A, B, C, E1, and E2). We investigated battery E2 in this study.

To evaluate process resilience, we simulated process response to relatively challenging influent perturbations. Two types of storm flows were considered:

- A single storm event, and

- Multiple storm events with a long total duration

Zhu (2015) simulated operations through representative single daily storm events and concluded that the Calumet WRP typically operates with excess aeration. The current aeration rate of about $13.9 \mathrm{~m}^{3} / \mathrm{s}(42.3 \mathrm{mcfd})$ could be decreased by as much as $50 \%$ without adversely affecting operations. However, historical data indicate that long-term successive storm flows frequently occur. (These storms are described in more details in the methodology section and the Supporting Information, Fig. S1). Influent to the Calumet WRP includes storm flow from the tunnel and reservoir plan (TARP), which is 
part of the local stormwater management system. Although TARP provides a buffer that reduces the magnitude of major storm events, in doing so it also increases the duration of storm flows, which means there can be above average flow even during dry-weather days.

As a result, a rapid succession of storm events can lead to especially challenging conditions, and it is important to understand the impact of these storm flows on process resilience. To evaluate these kinds of long-term perturbations, we tested the following hypothesis: Process resilience will not significantly change even after a 50\% decrease in aeration and the process can still successfully manage long-term storm flows. The next section describes how representative long-term storm events were synthesized and simulated using a WRP model to evaluate process response.

\section{Methods}

The three major tasks that comprised this study were the historical data inventory, WRP model simulation, and resilience quantification. Data inventory and model simulation are only briefly described here, more detailed information is provided by Zhu (2015).

\subsection{Historical data inventory}

For this study we did not have access to high frequency (more detailed than daily resolution) dynamic data for the Calumet WRP. Therefore, to synthesize storm flows we used daily and dynamic (hourly samples) flow data from the Stickney WRP (MWRDGC 2012a and 2012b) and daily data from the Calumet WRP (MWRDGC 2013). Based on a cross-correlation test (cross-correlation coefficient of about 0.6 ; at the $95 \%$ confidence 
level the critical value is 0.1 ), these two MWRDGC facilities share a similar flow pattern (Fig. S2). In previous work Zhu (2015) simulated single storm events (including changes in flow and influent concentrations) at flowrates of 2.6 (60 mgd), 3.5 (80), 4.4 (100), and $5.3(120) \mathrm{m}^{3} / \mathrm{s}$, to represent the range of relatively high flowrate $\left(2.3 \sim 5.7 \mathrm{~m}^{3} / \mathrm{s}\right)$ into the Calumet WRP. Based on dynamic data from the Stickney WRP, individual storms can be characterized by their event duration (duration time for a single storm flow), peak duration (elapsed time during peak flow), and amplitude (ratio of peak flow to initial minimum flow) (Fig. S3). Although a single, challenging storm flow will have relatively longer event duration and peak duration, it is unlikely that maximum values of event duration and peak duration occur simultaneously. Therefore, we defined a challenging single storm flow as an event duration of $22 \mathrm{~h}$ and a peak duration of $8 \mathrm{~h}$ based on third quartile values from their respective distributions. The amplitude was adjusted to represent the different flowrates.

In an attempt to use representative influent concentrations in the model, changes in the influent flow were correlated with changes in the influent concentrations $\left(\mathrm{SS}, \mathrm{CBOD}_{5}\right.$, TKN, VSS/SS, and $\mathrm{NH}_{3}-\mathrm{N} / \mathrm{TKN}$ ) based on regression equations developed from the historical data. Correlation coefficients were less than 0.5 (Fig. S4), which means that extreme (high or low) concentrations were excluded in this study. We address this issue further in the discussion of future work. No other influent concentrations were modified. Specifically, for the GPS-X process simulation model we used (the mantis model described below), we retained default values for influent dissolved oxygen (D.O. $=0$ ) and alkalinity (350 mg as $\left.\mathrm{CaCO}_{3} / \mathrm{L}\right)$. 
In the present study, we adopted a similar method to that used by Zhu (2015) for single storm flow synthesis of $2.6,3.5,4.4$, and $5.3 \mathrm{~m}^{3} / \mathrm{s}$, but also considered the total duration of multiple successive storm events. To determine the total durations for each flowrate, we inventoried the historical Calumet daily flow data (MWRDGC 2013) (Fig. S1). For example, a daily average influent flowrate of $3.5 \mathrm{~m}^{3} / \mathrm{s}$ can be associated with an average total duration of successive storm flows of four days. Mean total durations for 2.6, 3.5, 4.4, and $5.3 \mathrm{~m}^{3} / \mathrm{s}$ are about $139,96,67$, and $46 \mathrm{~h}$, respectively; these total durations were then used to simulate corresponding successive storm flows (Fig. 1).

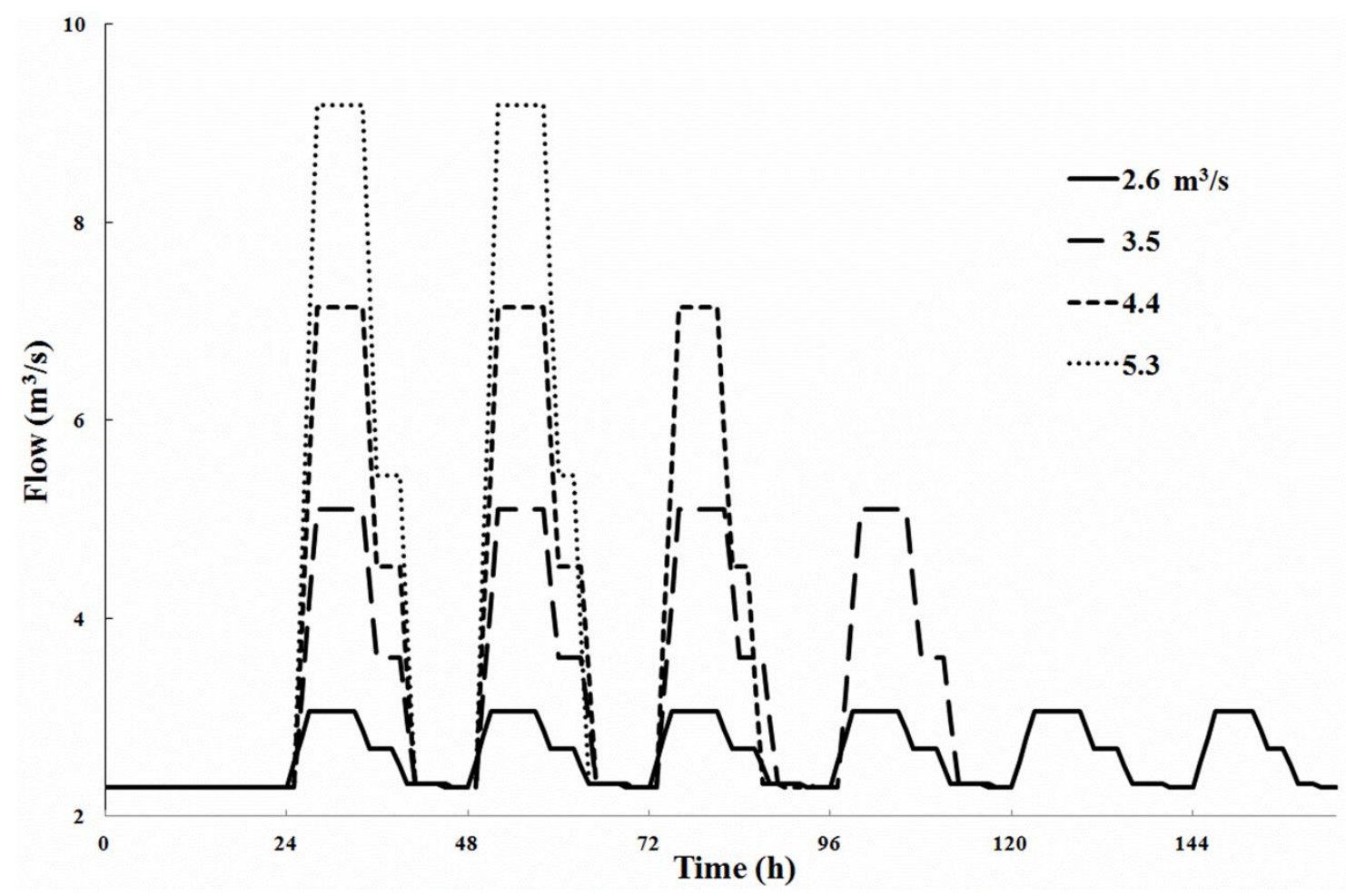

Fig. 1. Simulated 2.6, 3.5, 4.4, and $5.3 \mathrm{~m}^{3} / \mathrm{s}$ long-term successive storm flows. Note that the total duration decreases with increasing magnitude of flow. 


\subsection{WRP model simulation}

To simulate long-term successive storm flow, we developed a WRP process model using GPS-X ${ }^{\mathrm{TM}}$ (Hydromantis 2016). Battery E2 at the Calumet WRP includes ten aeration tanks and 12 secondary clarifiers; our simplified model included one large aeration tank (equal to the total volume of the ten aeration tanks) and one large clarifier (equal to the total volume of the 12 clarifiers). The aeration tank (PFR) was modeled as 30 CSTRs in series. The model used the simple carbon-nitrogen library, and the aeration tank and clarifier were based on the GPS-X mantis (Hydromantis 2016) and simple 1d models, respectively.

\subsection{Quantification of resilience}

Our two indicators of resilience, resistance and recovery time, were measured with respect to a critical constituent, which we defined as the parameter with the slowest rate of recovery after the perturbation. We initially considered four process parameters as potential indicators of process resilience: Effluent D.O., effluent ammonia, heterotrophic biomass (H.B.), and autotrophic biomass (A.B.). The effluent D.O. and ammonia concentrations were selected because they were sensitive to the aeration rate and to influent perturbations (Table S1 and Fig. S5). The H.B. and A.B. concentrations were selected because those microbial populations are critical to the process. These concentrations apply for the last CSTR in the model and do not consider by-pass flows, which can occur prior to or just after primary treatment. The historical data show that extremely high flows resulting in by-pass occurred about $2 \%$ of the time. As construction of TARP nears completion, the frequency of by-pass should decrease. 
Resistance and recovery time can be calculated as shown in Fig. 2. Resistance measures how that critical constituent responds to the successive storm flows during the event (Equation 1). Recovery time is the time required to return to a specified recovery index (\%, at concentration C1) (Fig. 2) once a storm-flow event ends. In this study, the critical recovery time was defined as the time required for the recovery index to reach 99\%. Although a WRP may not have to achieve $99 \%$ recovery index to successfully manage the next storm flow, we adopted that criterion for this study to better distinguish the recovery characteristics of the four process parameters. Lower percentages did not provide such a clear difference in recovery characteristics. For example, because the four process parameters all exceed $95 \%$ immediately after $2.6 \mathrm{~m}^{3} / \mathrm{s}$ successive storm flows at the current aeration rate, that recovery index cannot distinguish among recovery characteristics of the four process parameters. 


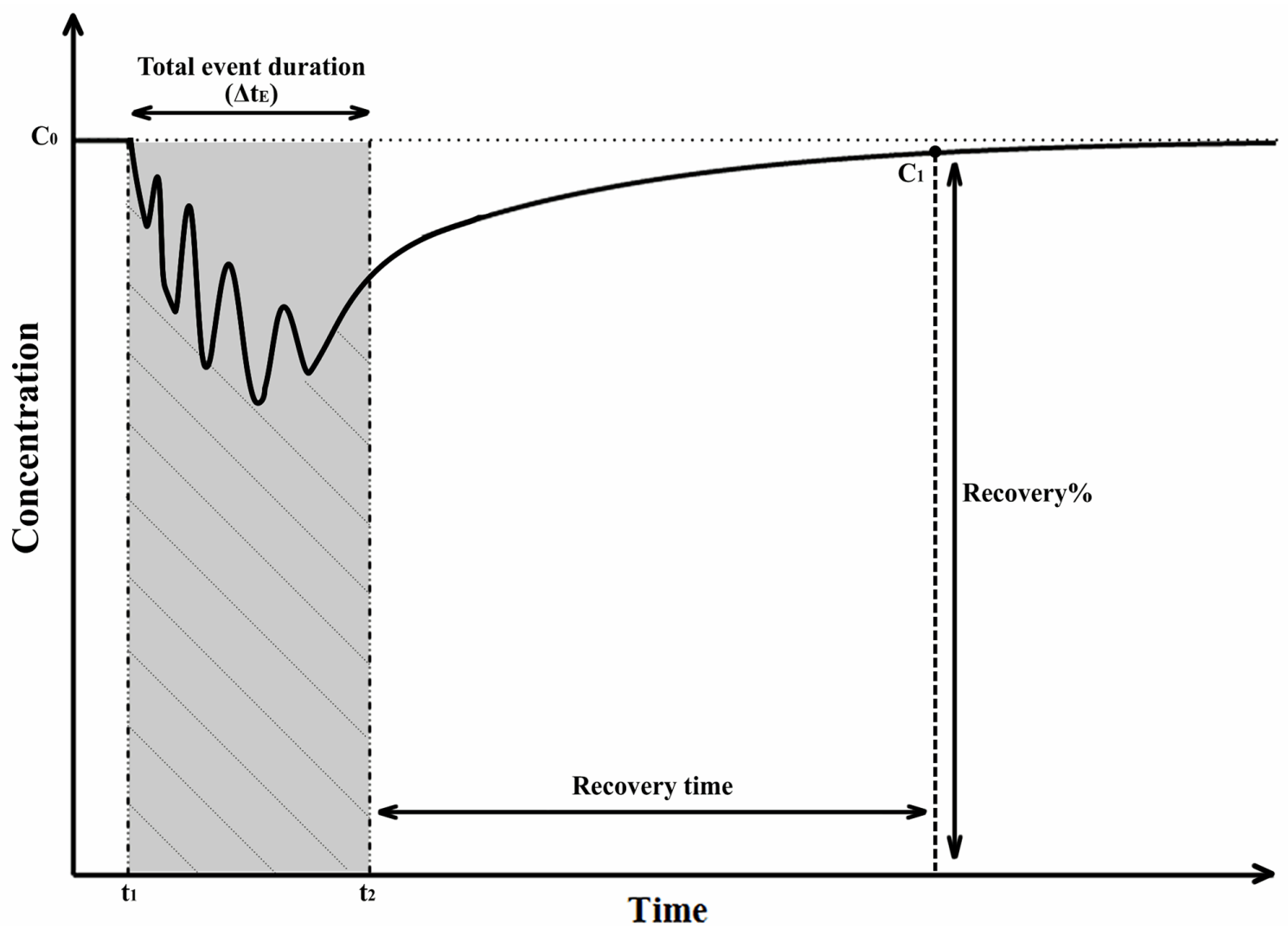

Fig. 2. Diagram of the method used to quantify resilience. The solid curve shows the concentration change throughout successive storm flows (from time $t_{1}$ to $t_{2}$ ); the top horizontal dotted line represents the initial steady-state concentration $\left(\mathrm{C}_{0}\right)$.

$$
\operatorname{Resistance}(\%)=\frac{\int_{t_{1}}^{t_{2}} C(t) d t}{C_{0} \times \Delta t_{E}} \times 100 \%
$$

Equation 1

$$
\text { Recovery index }(\%)=\frac{C_{0}-\left|C_{0}-C_{1}\right|}{C_{0}} \times 100 \%=\frac{C_{1}}{C_{0}} \times 100 \%\left(\text { if } C_{1}<C_{0}\right)
$$

Equation 2 


\subsection{Quality assurance and quality control (QA/QC)}

Because MWRDGC has a rigorous QA/QC program, no additional QA/QC assessment of the data was conducted before the analysis in this study. For the WRP modeling effort, sensitivity analysis of parameters was performed first; based on the results of that analysis, calibration and verification were used to improve the model accuracy (Fig. S6). Zhu (2015) provides more detailed information about these steps.

\section{Results and discussion}

\subsection{Recovery characteristics of major constituents}

Effluent D.O. and ammonia concentrations and H.B. and A.B. exhibit different recovery characteristics after successive storm flows (Fig. 3). For example, among these four constituents, D.O. achieves the highest recovery index (97.7\%) just at end of the 4.4 $\mathrm{m}^{3} / \mathrm{s}$ successive storm flows, followed by ammonia and H.B., which have a similar recovery index $(92.7 \%)$. The slowest recovery speed is associated with the A.B., which have the slowest growth rate. The H.B. recover gradually and reach a similar recovery index as D.O. after about seven days. In contrast with the other constituents, the ammonia concentration decreases initially and only starts to increase about ten hours later. The different shape of the ammonia recovery curve is likely due to the fact that ammonia recovery depends on the degree of dilution caused by the storm event and the hydraulic residence time. The D.O. begins to recover immediately as a result of aeration, and the A.B. and H.B. concentrations begin to recover immediately due to biosolids recycle. H.B. concentrations recover more rapidly because the return sludge continues to supply biomass even during successive storm flows. Compared to other constituents, A.B. 
concentrations start from a relatively low initial recovery index $(78.6 \%)$ with a relatively slow growth rate and therefore require a much longer time to recover. Fig. 3 shows only the $4.4 \mathrm{~m}^{3} / \mathrm{s}$ successive storm flow, but different flowrates lead to similar patterns of response although the amplitudes of the responses are different (Fig. S7). Based on these results, A.B. concentrations were used as the critical constituent to reflect plant response and determine resilience. (Total daily ammonia mass loading could be an important performance indicator and, in contrast with concentrations, a focus on loading would eliminate the effect of dilution. We examined that possibility, and discovered that relative to the other parameters, the process recovery speed for ammonia mass removal is faster. As a result, we conclude that A.B. concentration is the appropriate critical parameter for this assessment.)

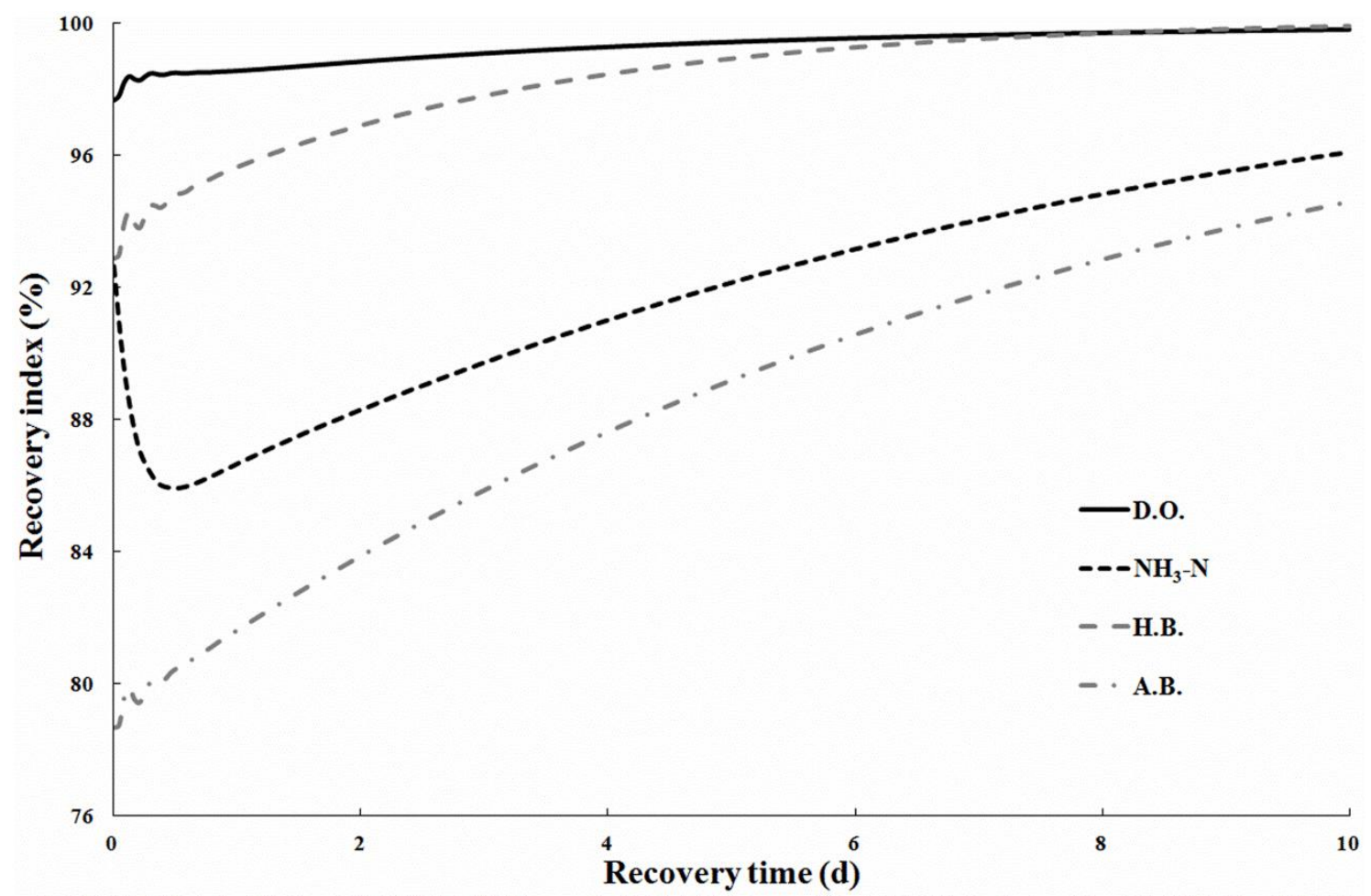


Fig. 3. Recovery characteristics of effluent D.O. and ammonia, heterotrophic biomass (H.B.), and autotrophic biomass (A.B.) after $4.4 \mathrm{~m}^{3} / \mathrm{s}$ long-term successive storm flows (aeration $\left.=13.9 \mathrm{~m}^{3} / \mathrm{s}\right)$.

\subsection{Relationships among flowrate, recovery characteristics, and aeration}

The responses of A.B. concentration to successive storm flows exhibit a similar pattern each day, but with increasing storm duration the recovery is slower (Fig. S8 and Fig. S9). The effect of aeration on A.B. recovery depends on the flowrate (Fig. 4). In general, the recovery index increases with increasing time at the same aeration rate and flowrate. For the $2.6 \mathrm{~m}^{3} / \mathrm{s}$ successive storm flows, as long as the amount of aeration is at least $6 \mathrm{~m}^{3} / \mathrm{s}$ (18 mcfd), the recovery index is relatively constant. Higher flows lead to a similar pattern for the recovery index but with much lower magnitude. It seems that the aeration rate does not have much effect on the initial fluctuation. For example, for the 5.3

$\mathrm{m}^{3} / \mathrm{s}$ successive storm flows, the recovery index decreases at the beginning regardless of the aeration rate; at the early times the surface looks like a "wall". There is a surprising pattern within the zone where lower aeration rates $\left(<6 \mathrm{~m}^{3} / \mathrm{s}\right)$ are associated with smaller recovery times (the front corner of the 3D figure). For example, at an influent flowrate of $3.5 \mathrm{~m}^{3} / \mathrm{s}$, the recovery index increases with decreasing aeration (recovery time $<2.2$ days). Similar patterns can be seen more clearly in $4.4(<5.6$ days $)$ and $5.3(<6.6$ days $) \mathrm{m}^{3} / \mathrm{s}$ flows. This pattern will be discussed in detail after quantification of the process resilience at these successive storm flows. Results described above provide a general understanding of recovery characteristics of the A.B. concentrations during different magnitudes of flows and aerations; the next step was to quantify process resilience. 

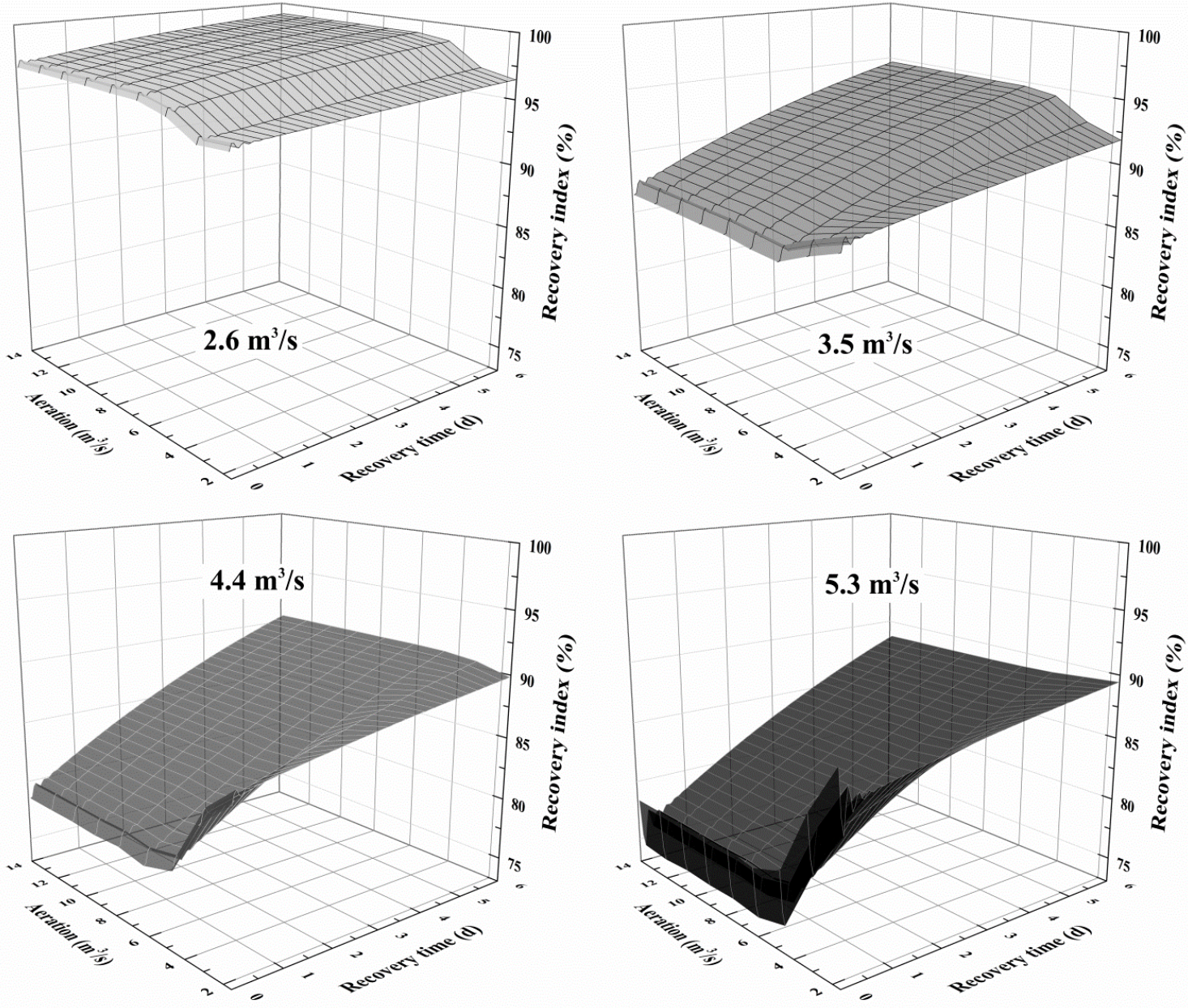

Fig. 4. Relationships among the A.B. recovery index and recovery time, and aeration for 2.6, 3.5, 4.4, and $5.3 \mathrm{~m}^{3} / \mathrm{s}$ long-term successive storm flows.

\subsection{Resilience quantification}

\subsubsection{Resistance}

The plant exhibits higher resistance to lower successive storm flows (Fig. 5). During $2.6 \mathrm{~m}^{3} / \mathrm{s}$ successive storm flows, the plant always maintains a resistance greater than $95 \%$, though there is a slight decrease of resistance when the aeration is below $5 \mathrm{~m}^{3} / \mathrm{s}(15$ mcfd). For simulated successive storm flows of $3.5,4.4$, and $5.3 \mathrm{~m}^{3} / \mathrm{s}$, and at the current aeration rate of about $13.9 \mathrm{~m}^{3} / \mathrm{s}$, resistances are about $87 \%, 80 \%$, and $75 \%$, respectively. 
As was the case for the recovery index, the resistance remains relatively constant when the aeration rate is above $6 \mathrm{~m}^{3} / \mathrm{s}$ (18 mcfd) for all magnitudes of successive storm flows. However, when the aeration rate is below $5 \mathrm{~m}^{3} / \mathrm{s}$ during successive storm flows of 3.5 , 4.4 , or $5.3 \mathrm{~m}^{3} / \mathrm{s}$, the resistance increases with decreasing aeration rate. It seems reasonable that higher flowrate leads to lower resistance, but we did not expect to see that the process can maintain relatively high resistance levels at lower aeration rates. We believe this behavior stems from the Michaelis-Menten kinetic model of growth, which causes the specific growth rate for A.B. to shift between 0 - to $1^{\text {st }}$-order kinetics with respect to $\mathrm{NH}_{3}$ and/or D.O., depending on their concentrations relative to their halfsaturation constants. A more detailed description of this phenomenon is provided in the supporting information (Table S2, Fig. S10). We also revisit the relationship between aeration and resilience in a subsequent section on "Overall evaluation of resilience". 


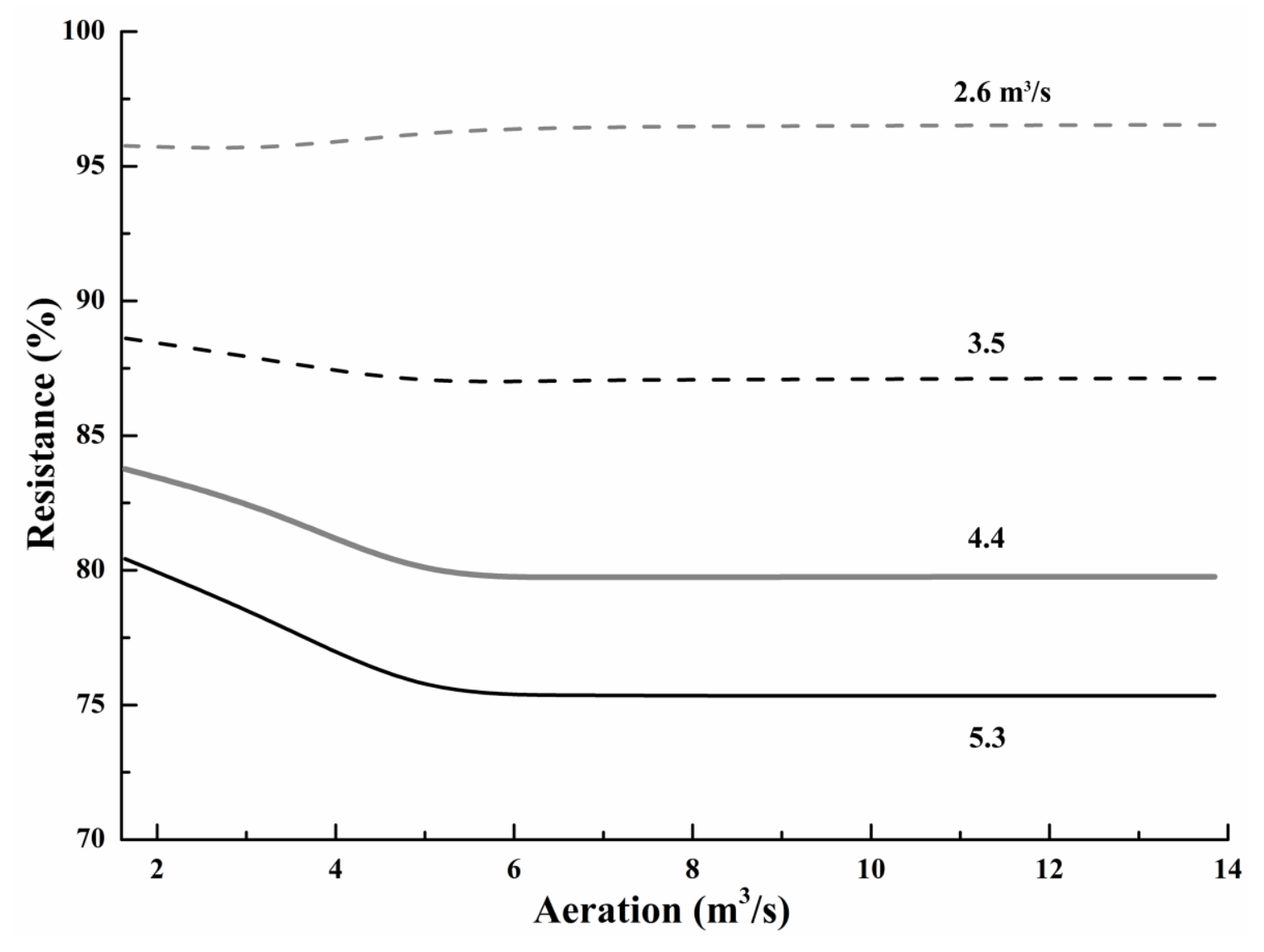

Fig. 5. Resistance (\%) of A.B. concentration to 2.6, 3.5, 4.4, and $5.3 \mathrm{~m}^{3} / \mathrm{s}$ long-term successive storm flows at different aeration rates at the Calumet WRP.

\subsubsection{Critical recovery time}

Larger flows are associated with longer critical recovery times for A.B. concentration, and lower aeration rates require even more time (Fig. 6). In general, and in agreement with the observations about the resistance, critical recovery time is relatively insensitive to the aeration rate when the aeration rate is above about $6 \mathrm{~m}^{3} / \mathrm{s}$. For example, for the 2.6 $\mathrm{m}^{3} / \mathrm{s}$ successive storm flows, the plant requires about 5.6 days to reach the $99 \%$ recovery index at the current aeration rate $\left(13.9 \mathrm{~m}^{3} / \mathrm{s}\right)$, and that time remains at a similar level $(6.4$ days, only a $6 \%$ increase) even when there is about a $57 \%$ decrease (to $6 \mathrm{~m}^{3} / \mathrm{s}$ ) in the 
aeration rate. After successive storm flows of $3.5,4.4$, and $5.3 \mathrm{~m}^{3} / \mathrm{s}$ it requires about 16 , 21 , and 23 days, respectively, to reach the $99 \%$ recovery index. When the aeration rate is below $5 \mathrm{~m}^{3} / \mathrm{s}$, the critical recovery time increases substantially as the aeration rate decreases; at such low aeration rates the D.O. supply limits recovery. For example, when the process experiences a $4.4 \mathrm{~m}^{3} / \mathrm{s}$ successive storm flow event, and when aeration has been decreased from $6.6(20 \mathrm{mcfd})$ to $3.3(10) \mathrm{m}^{3} / \mathrm{s}$, the process critical recovery time increases from 16 days to about one month. Even though the incremental increase in flowrate from one simulated successive storm flow to the next is the same (about 0.9 $\mathrm{m}^{3} / \mathrm{s}$ ), the incremental change in the critical recovery time decreases with increasing flowrate (Fig. 6).

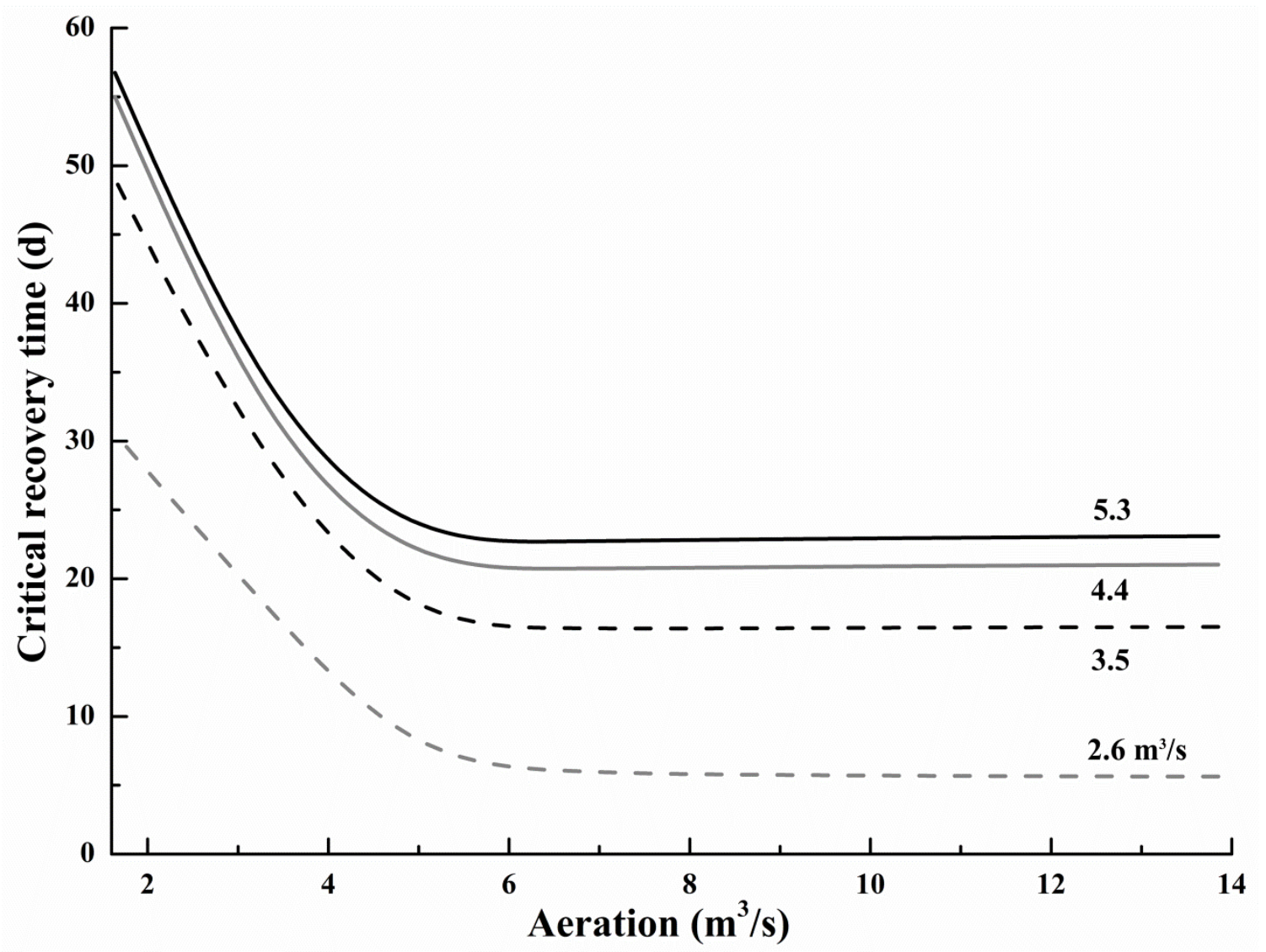


Fig. 6. Critical recovery time of A.B. concentration to 2.6, 3.5, 4.4, and $5.3 \mathrm{~m}^{3} / \mathrm{s}$ longterm successive storm flows at different aeration rates at the Calumet WRP.

\subsection{Overall evaluation of resilience}

In general, larger flowrates lead to lower process resilience, but the amplitude and total duration of a storm event have different effects on process resilience. From the resilience perspective, the amplitude appears to be more important than does the total duration of the storm. Furthermore, as long as the aeration rate is above $6 \mathrm{~m}^{3} / \mathrm{s}$, there is not a significant effect on process resilience. In other words, for this WRP model the aeration rate could be reduced to $6 \mathrm{~m}^{3} / \mathrm{s}$ and process resilience could be maintained. Although resistance and critical recovery time share similar patterns in response to

aeration rates below $6 \mathrm{~m}^{3} / \mathrm{s}$, as noted previously, the implications of those patterns are opposite from each other with respect to process resilience. Lower resistance means a greater deviation from the original operating state, but lower critical recovery time implies a faster return to the original state. This result could be interpreted based on a model of the stability landscape (Fig. 7), which has been used to describe engineering resilience associated with species concentrations (Peterson et al. 1998). A storm-flow event can alter the state of the process (represented by the ball) from its initial steadystate; larger successive storm flows push the ball to a higher point, resulting in lower resistance (resilience) (Fig. 7(a)). The resistance is inversely proportional to the height of the ball. After the event passes, the ball returns to the initial steady-state condition. Larger successive storm flows push the ball farther away from the initial steady-state condition, and lead to longer recovery times, which indicate lower resilience (Fig. 7(b)). 
However, the system becomes more complicated when the aeration rate is considered. Although A.B. concentration decreases with decreasing aeration rate, the oxygen is not a limiting parameter for keeping a dynamic mass balance of A.B. in the aeration tank until the aeration rate is below $6 \mathrm{~m}^{3} / \mathrm{s}$. However, when the rate is below $6 \mathrm{~m}^{3} / \mathrm{s}$, the recovery (growth + return) of A.B. cannot rapidly make up its loss, and there is a significant increase in the recovery time; there is a loss of process resilience. As a result, a change in aeration affects the landscape topography significantly more at lower aeration rates $(<6$ $\mathrm{m}^{3} / \mathrm{s}$ ), and the slope increases with increasing aeration rate (Fig. 7(c)). As the aeration rate decreases from 13.9 to $6 \mathrm{~m}^{3} / \mathrm{s}$, the landscape topography does not change a lot; the change becomes significant as the aeration rate is below $6 \mathrm{~m}^{3} / \mathrm{s}$. For the same flowrate (for example, $5.3 \mathrm{~m}^{3} / \mathrm{s}$ ), the ball moves higher, but it covers a much smaller distance in the horizontal direction at higher aeration rates. At lower aeration rates $\left(<6 \mathrm{~m}^{3} / \mathrm{s}\right)$, the situation is just the opposite, where the ball moves to a point at a relatively lower vertical level, much farther from its origin in the horizontal direction. Therefore, the recovery time and resistance remain the same along the aeration profile above $6 \mathrm{~m}^{3} / \mathrm{s}$, but significantly increase with decreasing aeration rate in the lower range $\left(<6 \mathrm{~m}^{3} / \mathrm{s}\right)$. From the perspective of storm flow, at the same aeration rate (for example, $13.9 \mathrm{~m}^{3} / \mathrm{s}$ ), a larger flowrate pushes the ball farther from its original steady-state, resulting in longer recovery time and smaller resistance. As previously mentioned, the intervals between adjacent states from 2.6 to $5.3 \mathrm{~m}^{3} / \mathrm{s}$ are not equal, but decreasing. There are at least two mechanisms that could explain this observation: Larger successive storm flows have relatively shorter total duration, which result in unequal increments; the relationship between resilience and magnitude of successive storm flows is non-linear. We do not 
know whether or not both of these reasons play important roles; addressing this question will be part of future work. Overall, it is not a contradiction that resistance and recovery time increase with decreasing aeration rate once the aeration rate drops below $6 \mathrm{~m}^{3} / \mathrm{s}$.

The concepts of resistance and recovery time follow a similar pattern, but they have different applications. For example, resistance provides more useful information if the purpose is to examine the effect of an external factor, such as a storm event, on process resilience (Fig. 7). However, if the process change results from an internal factor, such as aeration rate, measuring resistance does not provide very useful information about resilience. In contrast, the critical recovery time provides useful information about the effects of aeration or storm events on process resilience. Therefore, we used the critical recovery time to measure resilience as described in the next section. 


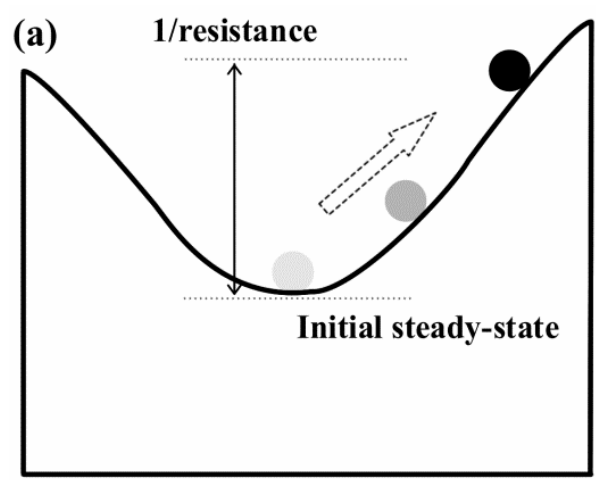

\section{(c)}

(b)
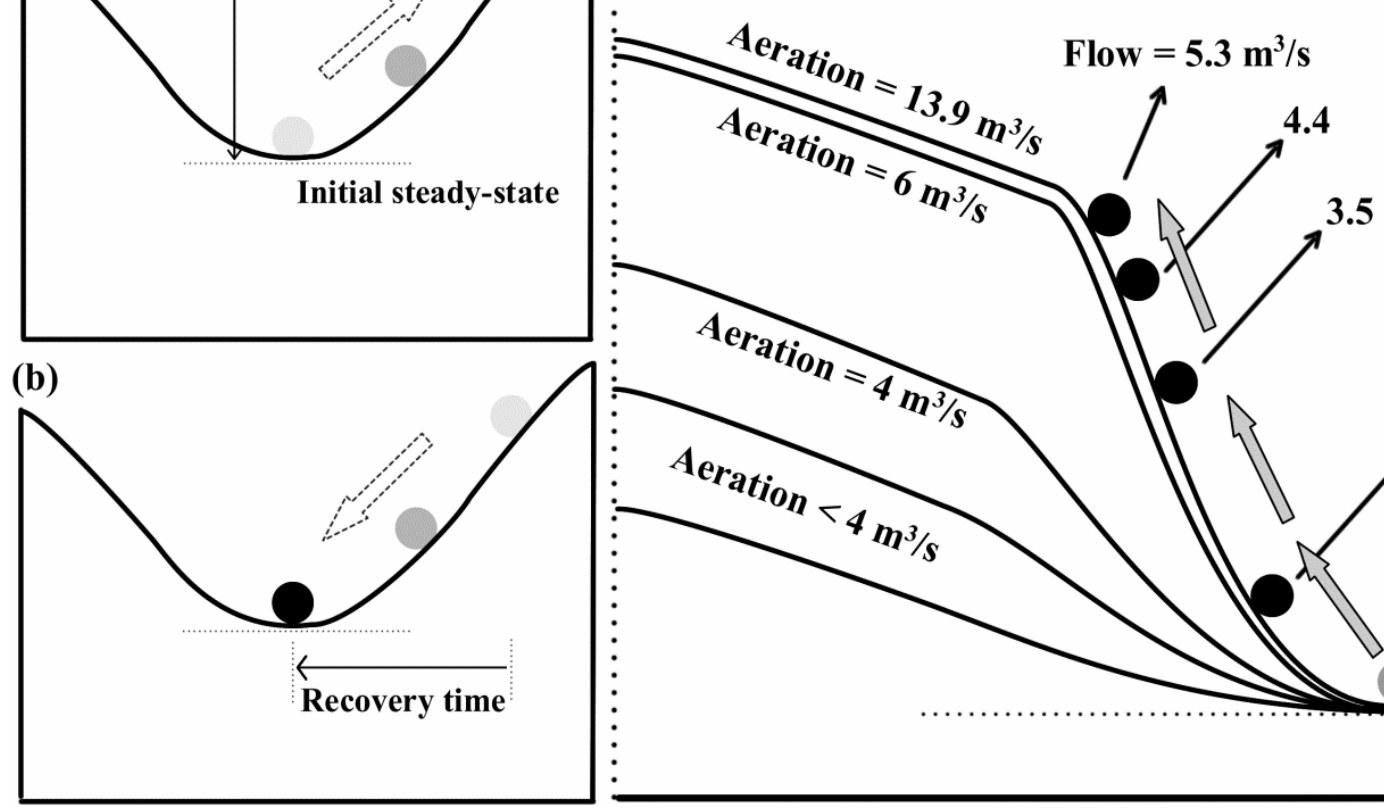

\section{,}
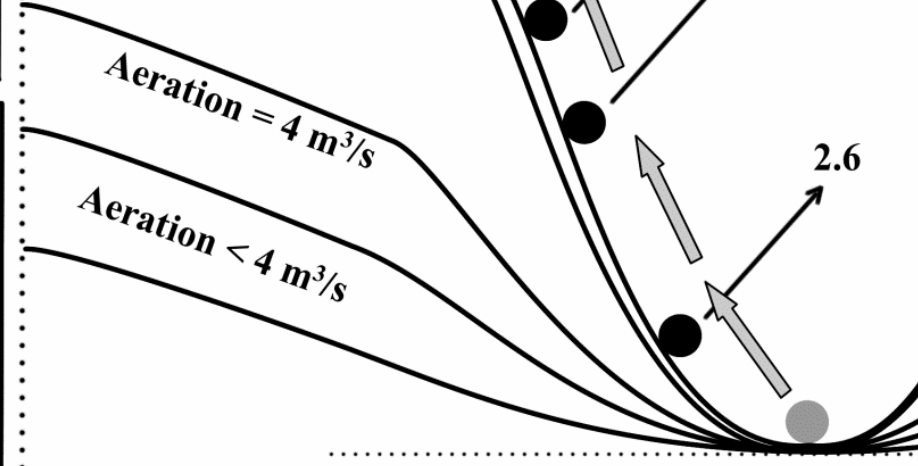

Fig. 7. A conceptual diagram of process stability (adapted from Peterson et al. 1998), where the ball represents the state of the process,

and the topography of the curve depends on the aeration rate. (a) Resistance describes how far the process strays from its initial steady-state as a result of a perturbation; a lower height of the ball represents higher resilience ( $\propto$ resistance). (b) Recovery time describes how fast the process returns to the initial steady-state; a shorter time represents higher resilience ( $\propto 1 /$ recovery time). (c) The aeration rate alters the landscape topography, and a higher aeration rate leads to a bigger slope. The left side shows how larger successive storm flows lead to a higher 
height of the ball at the same aeration rate. The right side shows how for the same storm flow, the aeration rate affects behavior of the ball; the landscape topography seldom changes when the aeration rate is above $6 \mathrm{~m}^{3} / \mathrm{s}$, but significantly changes at a lower aeration rate $\left(<6 \mathrm{~m}^{3} / \mathrm{s}\right)$. Note that the landscape model shown here is only semi-quantitative. 
In summary, larger flowrates and lower aeration rates can lead to lower process resilience. For the Calumet WRP, an aeration rate above $6 \mathrm{~m}^{3} / \mathrm{s}$ seems to be critical for maintaining process resilience.

Process resilience, inversely proportional to the critical recovery time, is a function of the aeration rate (Fig. 8), but it is important to keep in mind that the definition of engineering resilience involves the concept of maintaining function efficiency (Holling 1996). In other words, even if the amount of resilience can be quantified, it will be meaningless if the WRP cannot satisfy permit limits. Therefore, we also investigated the effluent quality (ammonia, $\mathrm{CBOD}_{5}$, SS, and D.O.) during $2.6,3.5,4.4$, and $5.3 \mathrm{~m}^{3} / \mathrm{s}$ longterm successive storm flows at different aeration rates. The Calumet plant can continue to meet all the permit requirements even after aeration savings of 50\%, 49\%, 47\%, and $44 \%$ (black circles in Fig. 8), respectively. These saving values were based on a simple total aeration reduction; higher savings could result if more sophisticated control strategies (such as D.O. and MLSS monitoring and controls) are applied. When the effluent quality can be maintained (solid curves in Fig. 8), the influence of successive storms (flowrate and concentration) dominates the change of process resilience, whereas aeration reduction does not significantly affect the amount of resilience. Overall, effluent quality requirements are satisfied when the aeration rate is above $6.9 \mathrm{~m}^{3} / \mathrm{s}$, and the plant is resilient. This conclusion applies to up to the maximum storm flows we investigated. Based on the historical data, extreme storm conditions that result in overflows occur about $2 \%$ of the time; these events were not included in our study. 


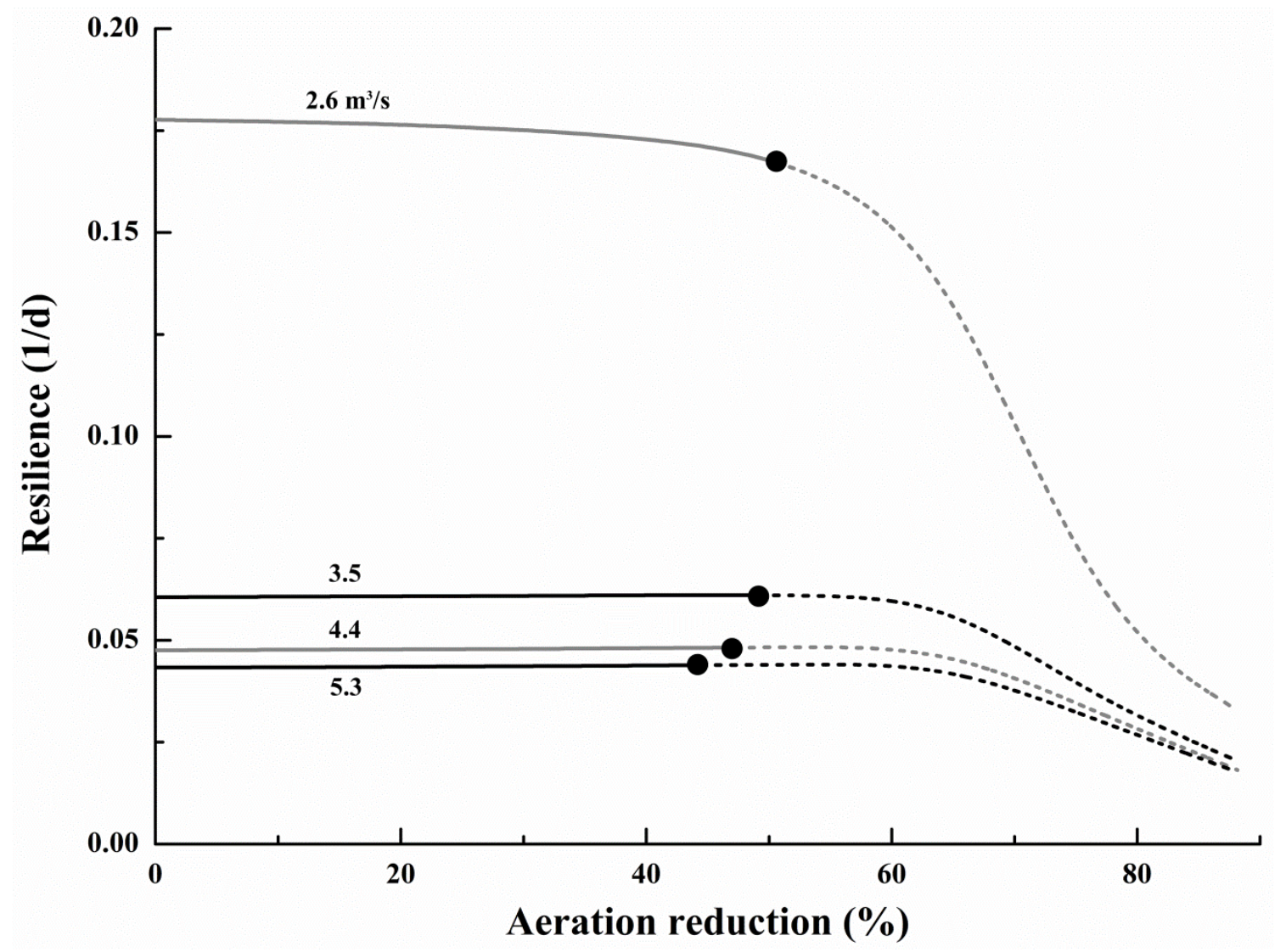

Fig. 8. Relationships among process resilience (1/critical recovery time), successive storm flows $\left(2.6,3.5,4.4\right.$, and $5.3 \mathrm{~m}^{3} / \mathrm{s}$ ), aeration reduction (from current $16.9 \mathrm{~m}^{3} / \mathrm{s}$ ), and effluent quality. Black circles are the upper limits of aeration savings at different successive storm flows; the solid curves represent that the effluent quality can satisfy all the permit requirements, whereas the dashed curves represent a lower effluent quality that cannot meet the requirements.

The relationship between the desired function efficiency (effluent permit requirements at a WRP) and decisions about efficient operation can also be better understood from Fig. 8. For example, consider a lower effluent quality requirement that allows a $70 \%$ reduction in aeration at $2.6 \mathrm{~m}^{3} / \mathrm{s}$ successive storm flows. The process 
operator can consider a wider range of aeration savings, but the process resilience decreases significantly. Because process resilience did not change substantially over the range of aeration reduction in our study, the balance between these choices was not an important issue, but it could become important in other applications.

\section{Conclusion}

Resilience describes the ability of the process to deal with influent perturbations. Long-term successive storm flows present relatively challenging conditions that can adversely affect process resilience. A better understanding of how resilience changes in response to long-term successive storm flows can provide operating benefits in terms of effluent quality control and operating costs. In this study, we used a WRP process model to simulate process response to long-term successive storm flows, and used resistance and recovery time to quantify process resilience based on autotrophic biomass concentration. We examined the influence of flowrate and aeration on the resilience, and evaluated the possibility of aeration savings with a consideration of effluent quality. Important results can be summarized as follows:

- Different constituents have different recovery times. Among the four tested constituents, effluent D.O. concentration recovers the most rapidly, followed by heterotrophic organisms and effluent ammonia; the concentration of autotrophic organisms has the slowest recovery.

- Resistance is a suitable way to evaluate resilience with respect to storm flows (an external factor), whereas the critical recovery time can be applied to examine both aeration (an internal factor) and storm flows. 
- Larger flowrates cause lower process resilience because they lead to lower recovery index and resistance; as a result the WRP has a much longer critical recovery time.

- At the Calumet WRP, process resilience is not sensitive to aeration when the aeration rate is above about $6 \mathrm{~m}^{3} / \mathrm{s}$, but when the aeration is below $6 \mathrm{~m}^{3} / \mathrm{s}$, lower aeration leads to lower resilience. The plant is resilient when the aeration rate is larger than $6.9 \mathrm{~m}^{3} / \mathrm{s}$. In summary, this study demonstrates that the Calumet WRP remains a resilient process even when operating at half the current aeration rate. We conclude that the WRP can operate in a more cost-effective way and it still has enough resilience to manage long-term successive storm flows and meet all the permit requirements. Although the specific results from this study are limited to the Calumet WRP, we believe the approach can be used to assess resilience at other facilities.

Results presented here suggest the need for additional studies, which we hope to conduct to help bring a more complete understanding of WRP process resilience:

- The relatively rare long-term successive storm flows examined in this study were based on average total durations and the influent concentrations represented an average response to the flow change. Subsequent studies should consider historical data to examine the effect of longer total duration flows and consider more extreme influent concentrations that could present greater challenges to process resilience. It would also be interesting to explore the effect of the influent D.O. on resilience; if future data show non-zero D.O. concentrations with influent stormwater, process resilience could be less sensitive to aeration.

- Aeration was studied because it plays an important role in A.B. recovery mechanisms. The influence of return sludge flow (RAS) on process resilience should also be 
investigated. This information might provide another option to better manage process resilience.

- The stability landscape model can successfully explain the relationships among process resilience (recovery time and resistance), aeration rate, and perturbations (storm flows), but this conceptual model provides a semi-quantitative description. A quantitative landscape model could be used to help make better control decisions.

\section{Acknowledgments}

This study, part of project funded by the National Science Foundation (NSF) (Award Number: 1035894), was conducted in collaboration with the Metropolitan Water Reclamation District of Greater Chicago (MWRDGC). The authors wish to thank Dr. Catherine O'Connor and Judith Moran, MWRDGC; for providing the data.

\section{Appendix A. Supplementary data}

Supplementary data related to this article can be found at http://dx.doi.org/

\section{References}

Botton, S., Van Heusden, M., Parsons, J. R., Smidt, H., Van Straalen, N. 2006. Resilience of microbial systems towards disturbances. Crit. Rev. Microbiol. 32, 101-112.

Cabrol, L., Malhautier, L., Poly, F., Le Roux, X., Lepeuple, A.-S., Fanlo, J.-L. 2012. Resistance and resilience of removal efficiency and bacterial community structure of gas biofilters exposed to repeated shock loads. Bioresource Technol. 123, 548-557.

CPS. 2010. CPS project on managing loosely coupled networked control systems with external disturbances: Wastewater processing. National Science Foundation award number: 1035894. (http://www.nsf.gov/awardsearch/showAward?AWD_ID=1035894, accessed July. 26, 2016). 
Grimm, V., Wissel, C. 1997. Babel, or the ecological stability discussions: An inventory and analysis of terminology and guide for avoiding confusion. Oecologia 109, 323-334.

Holling, C. S. 1973. Resilience and stability of ecological systems. Annu. Rev. Ecol. Syst. $4,1-23$.

Holling, C. S. 1996. Engineering resilience versus ecological resilience. Engineering within ecological constraints, 31-43.

Hydromantis. 2016. GPS-X is a modular, multi-purpose computer program for the modeling and simulation of municipal and industrial wastewater treatment plants. (http://www.hydromantis.com/GPS-X.html, accessed June 15, 2016).

Lopez, D. R., Brizuela, M. A., Willems, P., Aguiar, M. R., Siffredi, G., Bran, D. 2013. Linking ecosystem resistance, resilience, and stability in steppes of North Patagonia. Ecol. Indic. 24, 1-11.

Mabrouk, N., Mathias, J.-D., Deffuant, G. 2010. Computing the resilience of a wastewater treatment bioreactor. 2010 Fifth International Multi-conference on Computing in the Global Information Technology 185-188.

Marsolek, M. D., Kirisits, M. J., Gray, K. A., Rittmann, B. E. 2014. Coupled photocatalytic-biodegradation of 2,4,5-trichlorophenol: Effects of photolytic and photocatalytic effluent composition on bioreactor process performance, community diversity, and resistance and resilience to perturbation. Water Res. 50, 59-69.

MWRDGC. 2012a. Raw data from 2001 to 2009 of the Stickney WRP were provided by the Metropolitan Water reclamation District of Greater Chicago.

MWRDGC. 2012b. Raw hourly flow data in the Stickney WRP from October to December, 2011, and from May to August, 2012 was provided by the Metropolitan Water reclamation District of Greater Chicago.

MWRDGC. 2013. Raw data from 2002 to 2011 of the Calumet WRP were provided by the Metropolitan Water reclamation District of Greater Chicago.

Peterson, G., Allen, C. R., Holling, C. S. 1998. Ecological resilience, biodiversity, and scale. Ecosystems 1, 6-18.

Saikaly, P. E., Oerther, D. B. 2011. Diversity of Dominant Bacterial Taxa in Activated Sludge Promotes Functional Resistance following Toxic Shock Loading. Microb. Ecol. $61,557-567$.

Weirich, S. R., Silverstein, J., Rajagopalan, B. 2015. Resilience of secondary wastewater treatment plants: Prior performance is predictive of future process failure and recovery time. Environ. Eng. Sci. 32(3), 222-231. 
Weld, R. J., Singh, R. 2011. Functional stability of a hybrid anaerobic digester/microbial fuel cell system treating municipal wastewater. Bioresource Technol. 102, 842-847.

Wertz, S., Degrange, V., Prosser, J. I., Poly, F., Commeaux, C., Freitag, T., Guillaumaud, N., Roux, X. L. 2007. Decline of soil microbial diversity does not influence the resistance and resilience of key soil microbial functional groups following a model disturbance. Environ. Microbiol. 9, 2211-2219.

Westman, W. E. 1978. Measuring the inertia and resilience of ecological systems. BioScience 28, 705-710.

Zhu, J.-J. 2015. Cyber-physical system for a water reclamation plant: Balancing aeration, energy, and water quality to maintain process resilience. Ph.D. Dissertation, Illinois Institute of Technology, Chicago, IL. ProQuest/UMI. Publication Number: AAT 3733990 ; ISBN: 9781339224329. 


\section{Questions}

What is WRP process resilience?

Influence of storm flows?

\section{Influence of} aeration rate?

Cost-efficiency vs. Resilience vs. Effluent quality?

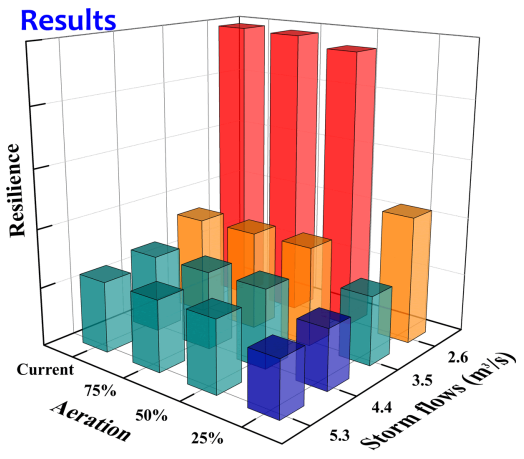

